Article

\title{
Effectively Measuring Student Leadership
}

\author{
Barry Z. Posner \\ Leavey School of Business, Santa Clara University, Santa Clara, CA 95030, USA; \\ E-Mail: bposner@scu.edu; Tel: +1-408-554-4634
}

Received: 24 August 2012; in revised form: 21 September 2012 / Accepted: 25 September 2012 /

Published: 12 October 2012

\begin{abstract}
With a worldwide sample of students $(\mathrm{N}=77,387)$, this paper reviews and analyses the psychometric properties of the Student Leadership Practices Inventory [1]. Modest to strong internal reliability coefficients are found across a number of different dimensions. Predictive validity of the instrument is supported, with the instrument being able to differentiate between effective and ineffective leaders using both self-reported and observer (constituent) data. Few significant differences are found on the basis of respondent gender, ethnicity, nationality, or institutional level (high school versus college). Implications for developing student leaders and future research are offered.
\end{abstract}

Keywords: leadership; student leadership; student leadership practices inventory; leadership development

\section{Introduction}

Leadership development is now an integral part of the educational program of college students, with courses and activities running the gamut from curricular classes offered by a variety of academic disciplines (like business, psychology, political science, history, military science, and education) to cocurricular programs offered by various student affairs offices (from admissions and athletics to student government, Greek affairs, and community service centers). This interest has spurred the development of a plethora of leadership books, materials, and experiential activities, along with surveys and instruments to measure and assess skills related to various leadership initiatives.

Many of the leadership development programs designed for college students are based upon studies and models that were developed with managers in business and public-sector organizations [2]. 
Serious questions have been raised about whether such models are applicable to college students and collegiate environments, which differ considerably from the environments in which managers and corporations operate. One way to address this issue has been the development of a number of new textbooks aimed at college students [3-6]. Still, the typical personal assessment techniques supporting these initiatives continue to be borrowed from other than collegiate environments. Brodsky's observation, more than 20 years ago, is still generally relevant: AValid instruments designed specifically for college students to measure their leadership development do not exist" [7]. The 8th Edition of Leadership Resources: A Guide to Training and Development Tools [8] listed 68 instruments "that are supported by technical data...[to measure] a variety of leadership skills and styles" but only the student version of the Leadership Practices Inventory [9] and another had a direct application to student populations. Some other instruments aimed at students assess social psychology aspects of leadership, like emotional intelligence [10], social responsibility [11], and attitudinal thinking [12].

The Student Leadership Practices Inventory (S-LPI) identifies specific behaviors and actions that students report using when they are at their "personal best as leaders." These behaviors are categorized into five leadership practices [13]:

1. Model the Way: Clarify values by finding your voice and affirming shared ideals; and set the example by aligning actions with shared values.

2. Inspire a Shared Vision: Envision the future by imagining exciting and ennobling possibilities; and enlist others in a common vision by appealing to shared aspirations.

3. Challenge the Process: Search for opportunities by seizing the initiative and by looking outward for innovative ways to improve; and experiment and take risks by constantly generating small wins and learning from experience.

4. Enable Others to Act: Foster collaboration by building trust and facilitating relationships; and strengthen others by increasing self-determination and developing competence.

5. Encourage the Heart: Recognize contributions by showing appreciation for individual

excellence; and celebrate the values and victories by creating a spirit of community.

Identified as practices common to successful leaders, these leadership practices correspond well to the developmental issues of importance for college students.

The objective of this paper is to update the analysis of the psychometric properties of the S-LPI [14], examining it along several dimensions to ascertain its reliability and validity. Several conclusions are drawn about student leadership development and challenges identified for both scholars and educators.

\subsection{Development of the Student LPI}

In developing the original version of the Leadership Practices Inventory, Kouzes and Posner [15] collected case studies from over 1,200 managers about their "personal-best experiences" as leaders. Content analyses of these case studies suggested a pattern of behaviors used by people when they were most effective as leaders. The development of a student version of the instrument followed the same 
case-study approach to investigate whether the leadership behaviors of college students were comparable with those of managers [16,17].

The initial student group consisted of outstanding student leaders at a large urban state university campus, as demonstrated by their being nominated by the college to participate in a nationally prominent collegiate leadership development experience. Four students from this group were randomly selected by year in school (junior or senior) and gender (male or female) to participate in this stage of the research project. The students were asked to think about their personal-best leadership experience and to make notes about the behaviors they believed were most critical to the success of this endeavor.

One week later, in a structured-interview format, each student responded to specific questions based on the personal-best survey reported in The Leadership Challenge [18]. The interviews lasted between thirty and ninety minutes; each was tape-recorded with the respondent's consent. The student interviews were content analyzed for themes (sentences or phrases) about leadership actions and behaviors. These themes were coded and tabulated into the five leadership categories that had been originally proposed from private and public sector managers. This analysis supported the contention that college student leaders did engage in these same leadership practices and revealed that this conceptual framework was relevant to the college student's leadership experience. Arendt followed a similar process for validating the appropriateness of the personal best leadership case study methodology and Student LPI for use with college students. She conducted in-depth, open-ended interviews with eight students about their personal experiences that might typify the five leadership practices. These interviews, she concluded, "established the existence of leadership behaviors in hospitality management and dietetics undergraduate students as students described leadership behaviors in each practice" [19].

Each statement on the original LPI was assessed in terms of its congruence with the themes derived from case studies of students' personal-best leadership experiences. The purpose of this coding was to determine which LPI statements accurately reflected the behavior of student leaders, thus facilitating the process of identifying terminology and concepts appropriate for use with a college-student population. Using this data, items were modified as necessary for use in the pilot version of the Student LPI.

The pilot version of the Student LPI consisted of 30 descriptive statements paralleling those found in the original LPI. Each of the five leadership practices was assessed with six statements and each measured with a five-point Likert-scale (where 1 meant "rarely" and 5 meant "very frequently"). The statements focused on leadership behaviors and on the frequency with which the individual engaged in those particular behaviors.

Twenty-three members from the college student senate at a small private suburban college campus were asked to serve as the test site for studying the pilot version. After completing the pilot version, they participated in an item-by-item discussion to determine whether any test statements were ambiguous, confusing, or not applicable to their experience as student leaders. This group also examined any potential social desirability basis in the statements. Of the thirty test items, twenty-five (83 percent) were unanimously determined to be clear and understandable and to consist of terminology and concepts that were within the experience of both students and student leaders. Ways to improve the somewhat problematic remaining items were also discussed and addressed. Five student leaders who had not been involved with any of the earlier Student LPI efforts were invited to 
participate in a focus-group discussion of the revised Student LPI; and only very minor editorial changes were subsequently made.

The Student LPI has two forms: Self and Observer. Each form consists of 30 statements-six statements to measure each of the five leadership practices. The forms differ only in terms of the individuals who complete them. The Self form is completed by the student leader himself or herself, and the Observer form is completed by a person who has directly observed the leadership behaviors of that student leader.

Findings from the most recent review of the S-LPI [20] were consistent with those found in previous studies [21-27]. Internal reliability coefficients in these studies were modest, and individual respondent characteristics did not account for differences in leadership practices (e.g., GPA, year in school, and academic major). Scores on the Student LPI differentiated between self-reports of effectiveness by respondents (both from a Self and Observer perspective). Not only is ongoing investigation of the basic psychometric properties of the instrument warranted but extending the analysis to broader population characteristics (e.g., ethnicity, nationality, and school setting) will shed greater light on understanding both student leadership and how it is developed.

\subsection{Methods and Sample}

This paper investigates the psychometric properties of the Student LPI. How well the instrument holds up across various sample populations is examined by looking at five post hoc possible hypotheses about the impact of personal differences. For example:

1. Do males and females differ in their leadership behaviors?

2. Does ethnic background result in behavioral differences in leadership?

3. Do students from the United States differ from students outside the United States in their leadership behaviors?

4. Do students in high school behave differently as leaders than students in college?

5. Does experience in leadership positions affect differences in leadership behaviors?

Beginning in 2007 the Student LPI has been largely administered online (electronically). This has resulted in the ability to accumulate a substantially large and robust sample population. This study looks at the S-LPI data collected between 2007 and 2010. This database contains responses from 77,387 students, including over 17,210 student leaders who completed the Self version and 60,177 who completed the Observer version. Because it is optional, not every respondent provides complete demographic data, and so the sample sizes vary.

In the overall sample, just over 28 percent of the respondents are in high school, 42.2 percent are in college, and the remaining 29.7 percent are in graduate school. Females comprise 61 percent of the sample. The majority of respondents are from the United States $(61.6 \%)$ and the remainders spread across 73 other countries (with most represented by Canada, China, Germany, Ireland, India, Mexico, Singapore, and Vietnam). Ethnic background is only asked of respondents from the United States and the vast majority indicate that they are White/Caucasian (64.4\%), with Asian/Pacific Islanders representing 16.3 percent of the sample, Hispanics/Latinos another 6.7 percent, Black/African Americans making up 5.7 percent, and 6.8 percent indicating "mixed race" as their ethnic category. 
Given a five-point Likert-scale, student leaders are asked to indicate the response which best described the number of opportunities they felt they had to be a leader. Just over one-third (36.3\%) indicated that they had "several" opportunities to be a leader, with 26.7 percent indicating that they had "many" such opportunities, and the remaining respondents (37.1\%) reporting either "some", "a few", or "no" such opportunities. As for the number of formal leadership development opportunities they have had (for example, classes, workshops, seminars, etc.) student leaders are generally well divided between "a few" (28.8\%), "some" (27.6\%), and "several" (30.0\%), with 4 percent indicating "none" and 9.5 percent indicating "many" opportunities.

\section{Results and Discussion}

Data on the internal reliability of the S-LPI are shown in Table 1. The overall Cronbach alpha coefficients on the Self version run from .69 to .80 and on the Observer version are all above 0.82. Reliability coefficients are also shown for Self and Observers on the basis of gender, nationality, ethnicity and institutional level (high school or college). These follow a similar pattern, with the scores of Observers being higher than those from Self respondents. All of the internal reliability coefficients on the Student LPI are above .61 and additional analyses (not shown) revealed that these coefficients did not increase if an item (statement/behavior) for any of the five leadership practices scales was deleted.

Table 1. Internal Reliability Analysis for the Student LPI (Cronbach Alpha coefficients).

\begin{tabular}{c|c|c|c|c|c}
\hline & Model & Inspire & Challenge & Enable & Encourage \\
\hline Self & .69 & .78 & .73 & .69 & .80 \\
\hline Observers & .82 & .86 & .84 & .82 & .87 \\
\hline Female/Self & .68 & .77 & .72 & .68 & .80 \\
\hline Male/Self & .66 & .76 & .69 & .66 & .80 \\
\hline Female/Observer & .84 & .87 & .86 & .83 & .88 \\
\hline Male/Observer & .81 & .84 & .82 & .81 & .87 \\
\hline U.S./Self & .63 & .74 & .68 & .66 & .80 \\
\hline U.S./Observer & .79 & .83 & .82 & .81 & .88 \\
\hline Foreign/Self & .71 & .80 & .76 & .72 & .79 \\
\hline Foreign/Observer & .82 & .86 & .84 & .83 & .86 \\
\hline Asian/Self & .72 & .80 & .75 & .69 & .78 \\
\hline Asian/Observer & .84 & .87 & .85 & .84 & .86 \\
\hline Black/Self & .63 & .72 & .69 & .63 & .79 \\
\hline Black/Observer & .79 & .84 & .82 & .80 & .88 \\
\hline Hispanic/Self & .62 & .74 & .73 & .63 & .81 \\
\hline Hispanic/Observer & .80 & .84 & .82 & .78 & .87 \\
\hline White/Self & .62 & .73 & .66 & .65 & .79 \\
\hline White/Observer & .79 & .83 & .82 & .81 & .87 \\
\hline High School/Self & .72 & .81 & .75 & .73 & .79 \\
\hline High School/Observer & .83 & .87 & .84 & .83 & .86 \\
\hline College/Self & .61 & .73 & .68 & .66 & .79 \\
\hline College/Observer & .80 & .83 & .82 & .82 & .86 \\
\hline
\end{tabular}


The data in Table 2 shows the mean and standard deviations for each leadership practice from student leaders and their observers, along with the rank order in terms of frequency for each group. Statistical comparisons ( $t$ tests) between the two groups indicated that scores from observers were significantly higher on each of the five practices than the scores provided by the student leaders. However, while the absolute differences between the two groups were statistically significant the pattern of responses (rank order) between the two groups is the same.

Table 2. Comparisons Between Self and Observers on the Student LPI.

\begin{tabular}{c|c|c|c|c|cc|c} 
& \multicolumn{2}{c}{ SELF $(\mathrm{N}=17,176)$} & \multicolumn{2}{c}{ OBSERVERS $(\mathrm{N}=59,825)$} \\
\hline Leadership Practice & Rank & \multicolumn{2}{|c|}{ Mean (StdDev) } & Rank & Mean (StdDev) & \\
\hline Model & $(3)$ & 21.6 & $(3.6)$ & $(3)$ & 22.8 & $(4.3)$ & $* * *$ \\
\hline Inspire & $(4)$ & 21.2 & $(4.2)$ & $(4)$ & 22.5 & $(4.7)$ & $* * *$ \\
\hline Challenge & $(5)$ & 21.2 & $(3.9)$ & $(5)$ & 22.5 & $(4.5)$ & $* * *$ \\
\hline Enable & $(1)$ & 23.9 & $(3.2)$ & $(1)$ & 24.5 & $(3.9)$ & $* * *$ \\
\hline Encourage & $(2)$ & 22.5 & $(4.1)$ & $(2)$ & 23.2 & $(4.7)$ & $* * *$ \\
\hline
\end{tabular}

$* * * p<.001$

Comparisons between female and male student leaders (self and observer) are shown in Table 3. Statistical analyses revealed no significant differences between these two groups of student leaders (Self), in either absolute response scores or rank order. From the perspective of observers, there were no statistically significant differences between female and male leaders on the leadership dimensions of Model, Inspire and Challenge. Males were seen as engaging significantly more frequently in Enable, while females were seen as engaging more frequently in Encourage. However, the rank order of the five practices as reported by female and male observers were identical.

Table 3a. Comparisons Between Females and Males (Self).

\begin{tabular}{c|c|c|c|c} 
& \multicolumn{2}{c}{ FEMALES $(\mathrm{N}=5,766)$} & \multicolumn{2}{c}{ MALES $(\mathrm{N}=3,543)$} \\
\hline Leadership Practice & Rank & Mean $(\mathrm{StdDev})$ & Rank & Mean (StdDev) \\
\hline Model & $(3)$ & $21.9(3.4)$ & $(3)$ & $21.7(3.4)$ \\
\hline Inspire & $(4)$ & $21.3(4.0)$ & $(4)$ & $21.7(4.0)$ \\
\hline Challenge & $(5)$ & $21.2(3.8)$ & $(5)$ & $21.7(3.7)$ \\
\hline Enable & $(1)$ & $24.1(3.1)$ & $(1)$ & $23.7(3.2)$ \\
\hline Encourage & $(2)$ & $22.9(4.0)$ & $(2)$ & $22.2(4.0)$ \\
\hline
\end{tabular}

Table 3b. Comparisons Between Females and Males (Observers).

FEMALES $(\mathrm{N}=18,569)$ MALES $(\mathrm{N}=12,033)$

\begin{tabular}{|c|c|c|c|c|c|}
\hline Leadership Practice & Rank & Mean (StdDev) & Rank & Mean (StdDev) & \\
\hline Model & (3) & $23.0 \quad(4.4)$ & (3) & $23.0 \quad(4.2)$ & \\
\hline Inspire & (4) & $22.8 \quad(4.8)$ & $(4)$ & $22.8 \quad(4.5)$ & \\
\hline Challenge & $(5)$ & $22.7 \quad(4.6)$ & $(5)$ & $22.7 \quad(4.4)$ & \\
\hline Enable & (1) & $24.7 \quad(3.9)$ & (1) & $24.4 \quad(3.9)$ & $* * *$ \\
\hline Encourage & (2) & $23.5 \quad(4.7)$ & (2) & $23.2 \quad(4.6)$ & $* * *$ \\
\hline
\end{tabular}

$* * * p<.001$ 
Comparisons between student leaders, and their observers, on the basis of ethnic background are shown in Table 4. This analysis is limited to respondents from the United States. Statistical differences were found on Inspire and Enable for student leaders. On Inspire most of this was due to Asians being lower on this leadership practice than the other groups and on Enable both Blacks and Hispanic were generally higher than the other ethnic groups on this leadership practice. From the perspective of Observers, there were statistically significant differences on three leadership practices: Model, Inspire and Challenge. Most of the differences on Model were due to Asians being viewed as engaging in this leadership practice much less so than the other groups. For both Inspire and Challenge, most of the differences were due to Hispanics being viewed as engaging in this leadership practice more so than the other groups.

Table 4a. Comparisons between United States Respondents on the Basis of Ethnic Background (Self).

\begin{tabular}{c|c|c|c|c|c|c}
\hline Leadership Practice & $\mathrm{N}$ & Model & Inspire*** & Challenge & Enable*** & Encourage \\
\hline Asian/Pacific Islander & 397 & 22.1 & 21.5 & 21.8 & 24.1 & 22.6 \\
\hline $\begin{array}{c}\text { Black/African } \\
\text { American }\end{array}$ & 497 & 22.4 & 22.6 & 21.9 & 24.6 & 22.8 \\
\hline Hispanic/Latino & 465 & 22.5 & 22.4 & 22.1 & 24.6 & 23.2 \\
\hline Mixed Race & 211 & 22.3 & 22.1 & 22.1 & 24.0 & 22.6 \\
\hline White/Caucasian & 4,322 & 22.3 & 22.0 & 21.7 & 24.1 & 22.7 \\
\hline
\end{tabular}

$* * * p<.001$

Table 4b. Comparisons between United States Respondents on the Basis of Ethnic Background (Observers).

\begin{tabular}{c|c|c|c|c|c|c}
\hline Leadership Practice & $\mathrm{N}$ & Model $^{* * *}$ & Inspire*** $^{* *}$ & Challenge*** & Enable & Encourage \\
\hline Asian/Pacific Islander & 1,192 & 23.8 & 23.7 & 23.4 & 25.2 & 24.1 \\
\hline $\begin{array}{c}\text { Black/African } \\
\text { American }\end{array}$ & 1,118 & 24.0 & 24.0 & 23.6 & 25.3 & 24.0 \\
\hline Hispanic/Latino & 1,365 & 24.4 & 24.3 & 24.0 & 25.5 & 24.3 \\
\hline Mixed Race & 646 & 24.0 & 23.8 & 23.4 & 25.1 & 24.1 \\
\hline White/Caucasian & 13,918 & 24.2 & 24.0 & 23.8 & 25.3 & 24.1 \\
\hline
\end{tabular}

$* * * p<.001$

The results shown in Table 5 examine the differences between students in the United States with those outside of the U.S. (foreign). In nearly all of the comparisons the responses from U.S. student leaders (self) and observers are significantly higher than those student leaders and their observers outside of the U.S. However, the shape of the distribution (as illustrated by the rank order of the five practices) for student leaders, as well as observers, is nearly the same, with only Inspire and Challenge being in a slightly different order for the two groups. 
Table 5a. Comparisons between Respondents in the United States and Outside the United States [Foreign] (Self).

UNITED STATES $(\mathrm{N}=6,000) \quad$ FOREIGN $(\mathrm{N}=3,336)$

\begin{tabular}{c|c|c|c|c|c}
\hline $\begin{array}{c}\text { Leadership } \\
\text { Practice }\end{array}$ & Rank & $\begin{array}{c}\text { Mean } \\
\text { (StdDev) }\end{array}$ & Rank & $\begin{array}{c}\text { Mean } \\
\text { (StdDev) }\end{array}$ & \\
\hline Model & $(3)$ & $22.3(3.3)$ & $(3)$ & $20.8(3.6)$ & $* * *$ \\
\hline Inspire & $(4)$ & $22.0(3.9)$ & $(5)$ & $20.4(4.2)$ & $* * *$ \\
\hline Challenge & $(5)$ & $21.8(3.6)$ & $(4)$ & $20.7(4.0)$ & $* * *$ \\
\hline Enable & $(1)$ & $24.0(3.1)$ & $(1)$ & $23.7(3.2)$ & $* * *$ \\
\hline Encourage & $(2)$ & $22.7(4.1)$ & $(2)$ & $22.5(3.9)$ & \\
\hline
\end{tabular}

Table 5b. Comparisons between Respondents in the United States and Outside the United States [Foreign] (Observers).

UNITED STATES $(\mathrm{N}=18,649) \quad$ FOREIGN $(\mathrm{N}=11,998)$

\begin{tabular}{c|c|c|c|c|c}
\hline $\begin{array}{c}\text { Leadership } \\
\text { Practice }\end{array}$ & Rank & $\begin{array}{c}\text { Mean } \\
\text { (StdDev) }\end{array}$ & Rank & $\begin{array}{c}\text { Mean } \\
\text { (StdDev) }\end{array}$ & \\
\hline Model & $(3)$ & $24.1(3.9)$ & $(3)$ & $21.2(4.3)$ & $* * *$ \\
\hline Inspire & $(4)$ & $24.0(4.2)$ & $(5)$ & $20.9(4.8)$ & $* * *$ \\
\hline Challenge & $(5)$ & $23.8(4.2)$ & $(4)$ & $21.0(4.5)$ & $* * *$ \\
\hline Enable & $(1)$ & $25.3(3.7)$ & $(1)$ & $23.5(4.0)$ & $* * *$ \\
\hline Encourage & $(2)$ & $24.1(4.6)$ & $(2)$ & $22.2(4.6)$ & $* * *$ \\
\hline
\end{tabular}

$* * * p<.001$

Comparisons between respondents in high school and college are shown in Table 6. The responses of college students were uniformly higher than those from high school students on all five leadership practices. This was true for both student leaders and their observers. The rank order of the practices, however, was relatively consistent between the two groups, with only Inspire and Challenge in opposite orders.

Table 6a. Comparisons between High School and College Respondents (Self).

\begin{tabular}{c|c|c|c|c|c|c}
\multicolumn{8}{c}{ HIGH SCHOOL $(\mathrm{N}=1,633)$} & \multicolumn{1}{c}{ COLLEGE $(\mathrm{N}=3,594)$} \\
\hline Leadership Practice & Rank & Mean (StdDev) & Rank & Mean (StdDev) & \\
\hline Model & $(3)$ & $20.9(3.6)$ & $(3)$ & $22.3(3.2)$ & $* * *$ \\
\hline Inspire & $(5)$ & $20.3(4.3)$ & $(4)$ & $22.0 \quad(3.8)$ & $* * *$ \\
\hline Challenge & $(4)$ & $20.5(4.0)$ & $(5)$ & $21.7(3.6)$ & $* * *$ \\
\hline Enable & $(1)$ & $23.7(3.3)$ & $(1)$ & $24.0(3.0)$ & $* *$ \\
\hline Encourage & $(2)$ & $22.5(4.0)$ & $(2)$ & $22.8(4.0)$ & $* *$ \\
\hline
\end{tabular}

$* * p<.01 * * * p<.001$ 
Table 6b. Comparisons between High School and College Respondents (Observers).

HIGH SCHOOL $(\mathrm{N}=6,400) \quad$ COLLEGE $(\mathrm{N}=8,503)$

\begin{tabular}{l|l|ll|l|ll|l}
\hline Leadership Practice & Rank & \multicolumn{2}{|l|}{ Mean (StdDev) } & Rank & Mean (StdDev) & \\
\hline Model & $(3)$ & 21.0 & $(4.4)$ & $(3)$ & 23.9 & $(4.0)$ & $* * *$ \\
\hline Inspire & $(5)$ & 20.6 & $(4.8)$ & $(4)$ & 23.8 & $(4.2)$ & $* * *$ \\
\hline Challenge & $(4)$ & 20.7 & $(4.6)$ & $(5)$ & 23.5 & $(4.2)$ & $* * *$ \\
\hline Enable & $(1)$ & 23.4 & $(4.1)$ & $(1)$ & 25.2 & $(3.8)$ & $* * *$ \\
\hline Encourage & $(2)$ & 22.1 & $(4.6)$ & $(2)$ & 24.1 & $(4.5)$ & $* * *$ \\
\hline
\end{tabular}

$* * * p<.001$

Student leaders were asked about how many opportunities they had experienced to be in the role of a leader. On a five-point response scale the alternatives were: None, Few, Some, Several, and Many. Combining these scores into approximately equal-sized groups resulted in three categories: Few, moderate, and many. Examining the frequency with which student leaders engaged in the five leadership practices revealed a statistically significant pattern. As shown in Table 7, the more opportunities student leaders reported experiencing to actually be leaders, the more frequently they indicated engaging in these leadership practices. Similarly, student leaders were asked about how many opportunities they had to develop their leadership skills, using a similar five-point scale as in the previous question about their opportunities to be leaders. Forming three approximately equal sized groups and investigating the frequency to which those within each group reported using the leadership practices revealed another consistent pattern. The more opportunities that student leaders reported having to develop their skills the more they reported engaging in each of the five leadership practices, as shown in Table 8. When these two variables - opportunities to be a leader and opportunities to develop leadership skills-were combined, the findings were consistent with the results from the separate analyses (see Table 9).

Table 7. Comparisons between Respondents by Opportunities to Be a Leader (Self).

\begin{tabular}{c|c|c|c|c}
\hline Leadership Practice & FEW $(\mathrm{N}=2,418)$ & MODERATE $(\mathrm{N}=2,365)$ & MANY $(\mathrm{N}=1,738)$ & \\
\hline Model & 20.7 & 22.1 & 23.1 & $* * *$ \\
\hline Inspire & 20.0 & 21.8 & 23.1 & $* * *$ \\
\hline Challenge & 20.2 & 21.7 & 22.8 & $* * *$ \\
\hline Enable & 23.6 & 24.0 & 24.3 & $* * *$ \\
\hline Encourage & 21.7 & 22.9 & 23.6 & $* * *$ \\
\hline$* * * p<.001$ &
\end{tabular}

Table 8. Comparisons between Respondents by Opportunities to Develop Leadership Skills (Self).

\begin{tabular}{c|c|c|c|c}
\hline Leadership Practice & FEW $(\mathrm{N}=2,142)$ & MODERATE $(\mathrm{N}=1,799)$ & MANY $(\mathrm{N}=2,580)$ & \\
\hline Model & 21.0 & 21.6 & 22.7 & $* * *$ \\
\hline Inspire & 20.3 & 21.2 & 22.7 & $* * *$ \\
\hline Challenge & 20.4 & 21.1 & 22.4 & $* * *$ \\
\hline Enable & 23.7 & 23.8 & 24.3 & $* * *$ \\
\hline Encourage & 21.7 & 22.6 & 23.4 & $* * *$ \\
\hline
\end{tabular}


Table 9. Comparisons between Respondents by Opportunities to Both Be a Leader and Develop Leadership Skills (Self).

\begin{tabular}{c|c|c|c|c}
\hline Leadership Practice & FEW $(\mathrm{N}=1,613)$ & MODERATE $(\mathrm{N}=3,546)$ & MANY $(\mathrm{N}=1,356)$ & \\
\hline Model & 20.5 & 22.0 & 23.2 & $* * *$ \\
\hline Inspire & 19.8 & 21.6 & 23.2 & $* * *$ \\
\hline Challenge & 20.0 & 21.5 & 23.0 & $* * *$ \\
\hline Enable & 23.6 & 24.0 & 24.4 & $* * *$ \\
\hline Encourage & 21.4 & 22.8 & 23.7 & $* * *$ \\
\hline
\end{tabular}

$* * * p<.001$

Several routes were explored toward investigating the predictive validity of the Student LPI. In the first instance, student leaders were asked about how strong they felt their leadership skills were compared with their peers. In the second instance, observers were similarly asked about how they felt the leadership skill level of their leaders was compared with his/her peers. In both instances respondents used a five-point response scale with these alternatives: Not well developed, somewhat undeveloped, similar with my (his/her) peer group, somewhat developed, and well developed. Three relatively equally-sized categories were subsequently created: Low, Moderate and High. The more developed, or stronger, that student leaders perceived their leadership skills to be compared with their peers the more they reported engaging in the five leadership practices. This finding was consistent between those with low and moderate skill levels and between moderate and high skill levels. This pattern was true from both the perspective of the student leaders as well as from the vantage point of their observers (Table 10).

Table 10a. Comparisons by Perceived Leadership Skills (Self).

\begin{tabular}{c|c|c|c|c}
\hline Leadership Practice & LOW $(\mathrm{N}=1,812)$ & MODERATE $(\mathrm{N}=2,897)$ & HIGH $(\mathrm{N}=1,817)$ & \\
\hline Model & 20.1 & 21.9 & 23.6 & $* * *$ \\
\hline Inspire & 19.2 & 21.6 & 23.7 & $* * *$ \\
\hline Challenge & 19.4 & 21.6 & 23.2 & $* * *$ \\
\hline Enable & 23.5 & 24.0 & 24.4 & $* * *$ \\
\hline Encourage & 21.1 & 22.8 & 23.9 & $* * *$ \\
\hline
\end{tabular}

$* * * p<.001$

Table 10b. Comparisons by Perceived Leadership Skills (Observers).

\begin{tabular}{l|c|c|c|c}
\hline Leadership Practice & LOW $(\mathrm{N}=5,100)$ & MODERATE $(\mathrm{N}=7,746)$ & HIGH $(\mathrm{N}=10,507)$ & \\
\hline Model & 18.8 & 22.2 & 25.7 & $* * *$ \\
\hline Inspire & 18.3 & 21.8 & 25.7 & $* * *$ \\
\hline Challenge & 18.4 & 21.8 & 25.5 & $* * *$ \\
\hline Enable & 21.8 & 24.0 & 26.5 & $* * *$ \\
\hline Encourage & 19.4 & 22.6 & 25.9 & $* * *$ \\
\hline$* * * p<.001$ & \multicolumn{3}{l}{}
\end{tabular}

Validity was also explored by examining if the frequency of leadership behavior made a difference in the engagement and satisfaction of the leaders' constituents (observers). Observers were asked these three questions: (1) "Overall, how satisfied are you with the leadership exhibited by the person you just reported about?"; (2) "When working with this leader, I am highly productive in what I do"; and, (3) 
"I am proud to tell others that I am working with this leader." These questions were asked using a five-point Likert scale with the following anchors on the first question (Not very satisfied, somewhat dissatisfied, neither dissatisfied or satisfied, somewhat satisfied, and very satisfied) and these anchors on the other two questions (strongly disagree, disagree, neither agree nor disagree, agree, and strongly agree). The responses to these three questions were combined to create a "positive work outcome" scale. Cronbach alpha for the scale was .84. In 2010 two additional questions were added to the survey ("I feel like this leader values my work" and "When working with this leader, I feel like I am making a difference around here") and for this sample these two items were added to the previous three questions for an "enhanced positive work outcome" scale (Cronbach alpha $=.89)$. Although the sample size for the latter analysis was about one-third of the former, the results were quite consistent. As shown in Table 11 observers (constituents) were significantly more positive about their organizations, their leaders, and their effectiveness (in getting them engaged) as the frequency by which they reported their student leaders to be using each of the five leadership practices.

Table 11a. Comparisons by Positive Work Outcome (Observers).

\begin{tabular}{c|c|c|c|c}
\hline Leadership Practice & LOW $(\mathrm{N}=4,076)$ & MODERATE $(\mathrm{N}=7,326)$ & HIGH $(\mathrm{N}=3,909)$ & \\
\hline Model & 19.0 & 23.0 & 26.6 & $* * *$ \\
\hline Inspire & 18.6 & 22.7 & 26.5 & $* * *$ \\
\hline Challenge & 18.7 & 22.6 & 26.4 & $* * *$ \\
\hline Enable & 21.7 & 24.6 & 27.4 & $* * *$ \\
\hline Encourage & 19.5 & 23.3 & 26.7 & $* * *$ \\
\hline$* * * p<.001$ & \multicolumn{4}{|}{}
\end{tabular}

Table 11b. Comparisons by Enhanced Positive Work Outcome (Observers).

\begin{tabular}{c|c|c|c|c}
\hline Leadership Practice & LOW $(\mathrm{N}=1,454)$ & MODERATE $(\mathrm{N}=2,552)$ & HIGH $(\mathrm{N}=1,470)$ & \\
\hline Model & 19.4 & 23.1 & 26.5 & $* * *$ \\
\hline Inspire & 18.9 & 22.8 & 26.4 & $* * *$ \\
\hline Challenge & 19.0 & 22.7 & 26.3 & $* * *$ \\
\hline Enable & 21.7 & 24.8 & 27.3 & $* * *$ \\
\hline Encourage & 19.6 & 23.4 & 26.8 & $* * *$ \\
\hline
\end{tabular}

$* * * p<.001$

\section{Conclusions}

The purpose of this study was to investigate the reliability and validity of the Student Leadership Practices Inventory. Using a database of nearly 78,000 students, across a variety of individual differences (self versus observers, gender, ethnicity, nationality, high school versus college), internal reliability analyses showed a fairly consistent set of Cronbach alpha coefficients generally at about the .70 level and above. While there were some statistical differences in leadership behavior on the basis of gender, ethnicity, and nationality they were relatively minor in comparison with the many similarities. Moreover, the patterns of responses, as indicated by the rank order of frequency, were quite consistent among all of the various possible combinations investigated. The Student-LPI meets the psychometric standards of reliability and validity [28]. Still, somewhat higher internal reliability coefficients for several practices would be desirable. 
Normative analyses of whether engaging in these leadership behaviors mattered (validity) was clearly affirmative. From the perspective of their observers (constituents) the more frequently student leaders were perceived as engaging in the five leadership practices they more positive were their observers about their organizations, leaders and effectiveness. That the more student leaders reported having both opportunities to be leaders and to develop their leadership skills the more they engaged in each of the five leadership practices supports the predictive validity of the instrument and conceptual framework.

Several practical observations can be drawn from this analysis. First, leadership matters. Those students who practice leadership are more effective from the perspective of their constituents than those who don't engage as frequently in key leadership behaviors and actions. Those student leaders, who saw themselves as most effective in comparison with their peers, consistently reported using each leadership practice more. Second, the findings from this study confirm previous investigations about the robustness of the Student LPI across various sample populations. The S-LPI in this study was relatively unaffected by various demographic qualities (e.g., gender, ethnicity, nationality, and educational level). This finding is at odds with other studies, using different measurement instruments, which have found differences based upon such factors as ethnicity and gender [29,30].

Future studies of more increasingly diverse college student populations will continue to help to further an understanding of both leadership and student development. It would be useful, for example, to look at more diverse populations, such as student body officers, officers in professional clubs, sports teams, peer educators, and even graduate students. Equally revealing would be studies investigating various socio-cultural differences, such as socioeconomic status, sexual identity, disability, and the like. Some of the differences between students in the United States and those from other countries may have been masked by lumping all of the foreign countries together, and this finding should be more fully explored in future studies. In this same regard the possible impact of language could be accounted for by having the Student LPI available in each student's native language. In addition, studies investigating the relationship between leadership and such factors as cognitive complexity, personality typology, thinking and learning styles would be instructive. For example, it has been demonstrated that the more students are engaged in learning the more use they make of the five leadership practices [31]. Finally, the unique contribution of the Student LPI to understanding student leadership could be examined in relationship to instruments examining more specific aspects of leadership.

In addition, studies examining the impact of various leadership development programs and classes, especially over time, would assist greatly in understanding just how leadership is developed. For example, in one study the use of a conceptual leadership framework and feedback was shown to enhance the effectiveness of the pledge education program and to significantly increase leadership practice scores in a pre- and post-test condition [32]. Leadership development, as a visible component of new member development, was postulated to serve as a path for better aligning the fraternity experience with the aspirations of the academic community. Studies investigating just how leadership development occurs would be invaluable not just for those involved and responsible for student leadership development but for people who provide leadership education for corporate, civic and community organizations.

Finally, leadership educators (and student personnel administrators broadly) can take comfort and even pride in knowing that leadership education programs and leadership classes are influencing the 
actual leadership behaviors that students report using [33]. More frequent leadership behavior appears related to the opportunity that students have to reflect on their leadership experience, and themselves, as leaders. These can be further facilitated through case studies, shadowing opportunities, journaling, guest speakers (role models), and advanced or follow-up experiences.

\section{References and Notes}

1. Kouzes, J.; Posner, B. The Student Leadership Practices Inventory; Pfeiffer: San Francisco, CA, USA, 2003.

2. Freeman, F.; Knott, K.; Schwartz, M. Leadership Education 1994-1995: A Sourcebook; Center for Creative Leadership: Greensboro, NC, USA, 1994.

3. Bratton, J.; Grint, K.; Nelson, D.L. Organizational Leadership; South-Western: Mason, OH, USA, 2004.

4. Daft, R. The Leadership Experience, 5th ed.; South-Western: Mason, OH, USA, 2010.

5. Komives, S.; Lucas, N.; McMahon, T. Exploring Leadership: For College Students Who Want to Make a Difference, 2nd ed.; Jossey-Bass: San Francisco, CA, USA, 2006.

6. The Leaders Companion: Insights on Leadership through The Ages; Wren, J.T., Ed.; Free Press: New York, NY, USA, 1995.

7. Brodsky, B. Development of a Modified Version of the Leadership Practices Inventory for Use with College Students. Unpublished masters' thesis; San Jose State University: San Jose, CA, USA, 1988.

8. Schwartz, M.; Gimbel, K. Leadership Resources: A Guide to Training and Development Tools; Center for Creative Leadership: Greensboro, NC, USA, 2000.

9. Kouzes, J.; Posner, B. The Student Leadership Practices Inventory; Pfeiffer: San Francisco, CA, USA, 2003.

10. Shankman, M.L.; Allen, S.J. Emotional Intelligent Leadership: A Guide for Students; Jossey-Bass: San Francisco, CA, USA, 2008.

11. Dugan, J.P.; Komives, S.R.; Segar, T.C. College student capacity for socially responsible leadership: Understanding norms and influences of race, gender, and sexual orientation. JSARP 2008, 45(4), 475-500.

12. Wielkiewicz, R.M. The leadership attitudes and beliefs scale: An instrument for evaluating college students' thinking about leadership and organizations. JCSD 2000, 41(3), 335-347.

13. Kouzes, J.; Posner, B. The Leadership Challenge: How to Make Extraordinary Things Happen, 5th ed.; Jossey-Bass: San Francisco, CA, USA, 2012.

14. Posner, B. A leadership development instrument for students: Updated. JCSD 2004, 45(4), 443-456.

15. Kouzes, J.; Posner, B. The Leadership Challenge: How to Keep Getting Extraordinary Things Done in Organizations; Jossey-Bass: San Francisco, CA, USA, 1987.

16. Brodsky, B. Development of a Modified Version of the Leadership Practices Inventory for Use with College Students. Unpublished masters' thesis; San Jose State University: San Jose, CA, USA, 1988. 
17. Posner, B.; Brodsky, B. A leadership development instrument for college students. JCSD 1992, 33(4), 231-237.

18. Kouzes, J.; Posner, B. The Leadership Challenge: How to Keep Getting Extraordinary Things Done in Organizations; Jossey-Bass: San Francisco, CA, USA, 1987.

19. Arendt, S. Leadership Behaviors in Undergraduate Hospitality Management and Dietetics Students. Unpublished doctoral dissertation; Iowa State University: Ames, IA, USA, 2004.

20. Posner, B. A leadership development instrument for students: Updated. JCSD 2004, 45(4), 443-456.

21. Adams, T.; Keim, M. Leadership practices and effectiveness among Greek student leaders. College Student Journal 2002, 34, 259-270.

22. Endress, W. An exploratory study of college students' self-efficacy for relational leadership: The influence of leadership education, cocurricular involvement, and on-campus employment. Unpublished doctoral dissertation; University of Maryland: College Park, MD, USA, 2000.

23. Mendez-Grant, M. A Study of Freshman Interest Groups and Leadership Practices at Texas Women's University. Unpublished PhD dissertation; University of North Texas: Denton, TX, USA, 2001.

24. Posner, B.; Brodsky, B. The leadership practices of effective RAs. JCSD 1993, 34(4), 300-304.

25. Posner, B.; Brodsky, B. Leadership practices of effective student leaders: Gender makes no difference. NASPA Journal, 1994, 31(2), 113-120.

26. Posner, B.; Rosenberger, J. Effective orientation advisors are leaders too. NASPA Journal, 1997, 35(1), 46-56.

27. Williams, E. Differences in Greek Leadership Styles; Unpublished research paper; Central Michigan University: Mount Pleasant, MI, USA, 2002.

28. Hair, J.; Anderson, R.; Tatham, R.; Black, W. Multivariate Data Analysis, 7th ed.; Prentice Hall: Upper Saddle River, NJ, USA, 2009.

29. Ospina, S.; Foldy, E. A critical review of race and ethnicity in the leadership literature: Surfacing context, power and the collective dimensions of leadership. The Leadership Quarterly 2009, 20, 876-896.

30. Carli, L.L.; Eagly, A.H. Leadership and gender. In The Nature of Leadership, 2nd ed.; Antonakis, J., Day, D., Eds.; Sage: Thousand Oaks, CA, USA, 2012; pp. 417-476.

31. Posner, B. Understanding the learning tactics of college students and their relationship to leadership. LODJ 2009, 30(4), 386-395.

32. Matsos, C. Student Leadership Development as a Supplement to College Fraternity Pledge Programs. Unpublished PhD dissertation; University of Alabama: Tuscaloosa, AL, USA, 1997.

33. Posner, B. A longitudinal study examining changes in students' leadership behavior. JCSD 2009, 50(5), 551-563.

(C) 2012 by the authors; licensee MDPI, Basel, Switzerland. This article is an open-access article distributed under the terms and conditions of the Creative Commons Attribution license (http://creativecommons.org/licenses/by/3.0/). 